\title{
http://bjas.journals.ekb.eg \\ Predictors and Outcomes of Ultra-Fast Extubation of Patients after Open Heart Surgeries
}

\author{
E.F.Makram ${ }^{1}$, A.A.Abd-El monem ${ }^{2}$, M.A.El-Gazar ${ }^{3}$ and E.M.Shaheen ${ }^{4}$ \\ ${ }^{1}$ AnaesthesiaDept., Faculty of Medicine, Benha Univ., Benha, Egypt \\ ${ }^{2}$ Internal Medicine Dept., Faculty of Medicine, Benha Univ., Benha, Egypt \\ ${ }^{3}$ Cardiothoracic SurgeryDept., Faculty of Medicine, Benha Univ., Benha, Egypt \\ ${ }^{4}$ Critical Care Medicine, Dept., Faculty of Medicine, Benha Univ., Benha, Egypt \\ E-Mail:Ebtehal516@gmail.com
}

\begin{abstract}
Ultra-Fast tracking extubation in cardiac surgery is an accepted technique due to improvement in resource utilization. It is not associated with increased postoperative morbidity or mortality. Nevertheless, it significantly reduces costs and resource utilization. A retrospective study of 240 patients operated upon between Jan, 2016 and Jan, 2019. Patients were divided into two groups: Group A, provided ultra-fast-track extubation $(n=120)$ and group B, provided conventional extubation $(\mathrm{n}=120)$. There was no significant difference between both groups as regard age and body weight. The type of operation and the degree of preoperative pulmonary hypertension were also not significantly different. The post-operative intensive care and hospital stay was significantly less in the fast-track group.Ultra-Fast tracking extubation in cardiac surgery is an accepted technique due to improvement in resource utilization, decreased intensive care and hospital stay without increasing operative morbidity or mortality .
\end{abstract}

Keywords: Predictors and Outcomes of Ultra-fast Extubation of Patients after Open Heart Surgeries.

\section{Introduction}

After open-heart surgeries, patients are directly transferred to the intensive care unit (ICU) and remain under careful control of experienced nurses, who are equipped with special knowledge and skills in managing and looking after such patients, until they recover consciousness and enjoy sufficient oxygenation and homodynamic

Early extubation of patients after open-heart surgery is supposed to have beneficial clinical effects besides economic advantages. Among these effects are comfort of patients, reduced respiratory complications, savings in costs, earlier return of patients to normal life, and easier engagement in activities (which in itself will prevent complications resulting from low mobility). It will be possible to decrease effectively the negative effects of positive pressure ventilation by reducing the period patients require for mechanical ventilation [2].

\section{Patients and methods}

This study was retrospective observational study. Data were collected from Cardiac Surgery Department data base.This research was intending to estimate the predictors\& outcome of ultra-fast track extubation (on the table or within 2 hours in the ICU) versus ordinary extubation (after 6 hours in the ICU). Data collected for patients who underwent open heart surgeries from January 2016 until January 2019.The studied sample was 240 patientsafter open heart surgeries meeting the entery criteria of the study divided into 2 equal groups , based on time of extubation ,calculated from the moment the patient entered the ICU until the extubation time:

*ultra-fast extubation (On table or Within 2 hours in ICU).

*Ordinary extubation (After 6hours in ICU).

The patients excluded were Patients with EF less than $50 \%$, Patients with severe pulmonary hypertension, Patients with complex cardiac disease, Adults patients requiring more than single valve replacement, Previous open heart surgeries, Patients who will return to the operating room for any reason (such as bleeding) and Patients who will need cardiopulmonary resuscitation after surgery.

The surgery of the studied sample was not urgent, and they had no previous open-heart surgery. The patients underwent the same protocols of anaethesia, cardioplegia and medications before surgery. In all of them, surgery had been performed through median sternotomy using cardiopulmonary bypass pumps. Their temperatures had been lowered to $32 \mathrm{C}^{\circ}$ during $\mathrm{CPB}$ and cold Ringer's solution used for cardioplegy. At the completion of surgery, patients had been immediately transferred to ICU and attached to volumetric ventilators with the identical specifications of intermittent mandatory ventilation, 10-12 breaths $/ \mathrm{min}$, tidal volume of $10 \mathrm{cc} / \mathrm{kg}$, and $100 \%$ FiO2. Nurses looking after patients provided all postoperative care under the supervision of charge nurses. After the patients woke up, they were extubated if they met all the standard clinical extubation criteria.

\section{Results}

There was non-significant value as regarding demographic characteristics between 2 groups.

Analysis of the association of sex between groups using Pearson chi-square test, in group 1 (UFTE) there were 82 males $(68.3 \%) \& 38$ females $(31.7 \%)$ while in group 2 (convential group) there were 80 males $(66.7 \%)$ $\& 40$ females $(33.3 \%)$ with $\mathrm{P}$ value 0.7 (non-significant) Table (1).

The independant t-test was used to characterize the sample and to analyze the variables of body weight of the studied groups giving $\mathrm{P}$ value 0.06 (table 2). Body weight in group 1 (UFTE) was ranging from 15 to $40 \mathrm{~kg}$ with mean value 22.21 and 17.26 standard deviation. Body weight in group 2 (convential group) was ranging 
from 17 to $44 \mathrm{~kg}$ with mean value 17.98and 16.82 standard deviation.

There was highly variable range of age giving nonsignificant $\mathrm{P}$ value $(0.1)$ analysed by indepentant $\mathrm{T}$-test.
The age of UFTE group was ranging from 0.8 year to 42 years with mean value 6.94 years and 8.84 SD. The age of convential group was ranging from 0.7 year to 42 years with mean value 5.36 years and 8.95 SD.

Table (1) is showing Comparison between the studied groups as regard demographic characteristics.

\begin{tabular}{|c|c|c|c|c|c|}
\hline \multirow[t]{2}{*}{ Variable } & & Group 1 (no.=120) & Group 2 (no.=120) & \multirow[t]{2}{*}{ Test } & \multirow[t]{2}{*}{$\mathbf{P}$} \\
\hline & & No. & No. & & \\
\hline \multirow[t]{2}{*}{ Sex } & Male & 68.3 & 66.7 & Pearson Chi- & 0.7 \\
\hline & Female & 31.7 & 33.3 & 0.1 & (INS) \\
\hline $\begin{array}{l}\text { Age } \\
\text { (years) }\end{array}$ & $\begin{array}{c}\text { Mean } \pm \text { SD } \\
\text { Range } \\
\text { Median }\end{array}$ & $\begin{array}{c}6.94 \pm 8.84 \\
(0.8-42) \\
4\end{array}$ & $\begin{array}{c}5.36 \pm 8.95 \\
(0.7-42) \\
2\end{array}$ & $\begin{array}{c}\text { Independent } \mathrm{t}- \\
\text { test } \\
\mathrm{t}=1.37\end{array}$ & $\begin{array}{c}0.1 \\
(\mathrm{NS})\end{array}$ \\
\hline $\begin{array}{l}\text { Body } \\
\text { Weight }\end{array}$ & $\begin{array}{c}\text { Mean } \pm \text { SD } \\
\text { Range }\end{array}$ & $\begin{array}{c}22.21 \pm 17.26 \\
6.5-68\end{array}$ & $\begin{array}{c}17.98 \pm 16.82 \\
7-72\end{array}$ & $\begin{array}{c}\text { Independent } \mathrm{t}- \\
\text { test } \\
\mathrm{t}=1.9\end{array}$ & $\begin{array}{l}0.06 \\
\text { (NS) }\end{array}$ \\
\hline
\end{tabular}

Analysis of association of time of $\mathrm{CPB}$ and time required for reperfusion with timing of extubation using Independent t-test (table 2). Analysis of time of CPB gave non-significant $\mathrm{p}$ value 0.9 as time of CPB in UFTE group had a range from 32 to 150 minutes with mean value 67.9 minutes and 18.37 SD. time of $\mathrm{CPB}$ in convential group had a range from 32 to 105 minutes with mean value 67.75 minutes and 18.64 SD.

Analysis of time required for reperfusion (ischemic time) also gave non-significant p value 0.8 with a range in UFTE group from 0 to 85 minutes with mean value 42.02 minutes and 19.57 SD . convential group gave a range from 0 to 85 minutes with mean value 42.53 minutes and 19.57 SD.

Table (2) Comparison between the studied groups as regard CBP \& Ish. Time.

\begin{tabular}{|c|c|c|c|c|c|c|}
\hline \multirow[t]{2}{*}{ Variable } & \multicolumn{2}{|c|}{ Group 1 (no.=120) } & \multicolumn{2}{|c|}{ Group $2($ no.=120) } & \multirow[t]{2}{*}{ Independent t-test } & \multirow[t]{2}{*}{$\mathbf{P}$} \\
\hline & Mean \pm SD & Range & Mean \pm SD & Range & & \\
\hline CBP & $67.9 \pm 18.37$ & $32-150$ & $67.75 \pm 18.64$ & $32-105$ & 0.07 & 0.9 \\
\hline Ischaemic Time & $42.02 \pm 19.57$ & $0-85$ & $42.53 \pm 19.57$ & $0-85$ & 02 & 0.8 \\
\hline
\end{tabular}

The independent t-test was used to characterize the sample and to analyze the association of extubation time with ICU stay of the studied groups giving $\mathrm{P}$ value 0.01 table (3), highly significant value.

The patients who underwent ordinary extubation; group 2 were longer in ICU stay in time ranging from 26 hours to 380 hours with mean value 81.6 hours and 70.2 standard deviation .

Patients who underwent UFTE in group 1 group 2 were shorter in ICU stay in time ranging from 26 hours to 280 hours with mean value 54.9 hours and 43.4 standard deviation.
The independent t-test was used to characterize the sample and to analyze the association of extubation time with hospital stay of the studied groups giving $\mathrm{P}$ value 0.03 table (3), significant value.

As regarding hospital stay; group 2(convential group) was longer than group 1(ultra-fast track extub. group) in the period of hospital admission .

Group 1, ultra-fast track extubation group was hospitalized in a range from 5 to 12 days with mean value 6.85 days with 1.4 standard deviation.

Group 2, convential group was hospitalized in a range from 5 to 18 days with mean value 7.43 days with2.65 standard deviation.

Table (3) Comparison between the studied groups as regard ICU stay and hospital stay.

\begin{tabular}{|c|c|c|c|c|c|c|}
\hline \multirow[t]{2}{*}{ Variable } & \multicolumn{2}{|c|}{ Group 1(no.=120) } & \multicolumn{2}{|c|}{ Group 2 (no.=120) } & \multirow[t]{2}{*}{ Test } & \multirow[t]{2}{*}{$\mathbf{P}$} \\
\hline & Mean \pm SD & Range & Mean \pm SD & Range & & \\
\hline ICU stay & $54.9 \pm 43.4$ & $26-280$ & $81.6 \pm 70.2$ & $26-380$ & $\begin{array}{c}\text { Independent } t \text {-test } \\
t=-3.52\end{array}$ & $\begin{array}{l}0.001 \\
\text { (HS) }\end{array}$ \\
\hline Hospital stay & $6.85 \pm 1.4$ & $5-12$ & $7.43 \pm 2.65$ & $5-18$ & -2.12 & $\begin{array}{l}0.03 \\
(\mathrm{SS})\end{array}$ \\
\hline
\end{tabular}

Analysis of the association of extubation timing and mortality rate between groups using Pearson chi-square test gave non-significant $\mathrm{P}$ value 0.7 Table (4). 
Group 1; ultra-fast track extubation group had mortality rate $4.2 \%$ as 5 patients died from 120 patients. Group 2; convential group had mortality rate 5\% as 6 patients died from 120 patients.

Table (4) Comparison between the studied groups as regard mortality.

\begin{tabular}{|c|c|c|c|c|c|c|c|}
\hline \multirow{2}{*}{$\begin{array}{l}\text { Group } \\
\text { Variable } \\
\end{array}$} & & \multicolumn{2}{|c|}{$\begin{array}{c}\text { Group 1 } \\
(\text { no.=120) }\end{array}$} & \multicolumn{2}{|c|}{$\begin{array}{c}\text { Group 2 } \\
(\text { no.=120) }\end{array}$} & \multirow[t]{2}{*}{$\begin{array}{c}\text { Pearson chi square } \\
\text { test }\end{array}$} & \multirow[t]{2}{*}{$\begin{array}{c}\text { P- } \\
\text { value }\end{array}$} \\
\hline & & No. & $\%$ & No. & $\%$ & & \\
\hline Mortality & $\begin{array}{l}\text { Yes } \\
\text { No }\end{array}$ & $\begin{array}{c}5 \\
115\end{array}$ & $\begin{array}{c}4.2 \\
95.8\end{array}$ & $\begin{array}{c}6 \\
114\end{array}$ & $\begin{array}{c}5 \\
95\end{array}$ & 0.1 & $\begin{array}{c}0.7 \\
(\mathrm{NS})\end{array}$ \\
\hline
\end{tabular}

\section{Discussion}

In the current study, there was a significant reduction in mean (SD) length of ICU stay between the UFTA and the conventional group, 54.9 (18.62) hours and 81.4 (33.58) hours respectively (p-value $<0.001$ ).

This is consistent with [5] which revealed that they found that early extubation was associated with a shorter ICU and total hospital stay, without differences in rates of tracheotomy or reintubation. These findings suggest that in our patient demographic, fast track post-operative management is both safe and effective [3].

Similar findings have been previously reported in [8] which revealed that the implementation of UFTA protocol appears to be feasible and safe. It has led to significant reduction in the length of ICU stay of adult patients undergoing elective cardiac surgical operations [4].

Fast track extubation following cardiac surgery is commonly employed as a means to facilitate rapid recovery and discharge from an intensive care unit, thereby reducing costs of expensive resources. This is consistent with [5] attributing the high costs of these surgeries to the lengthy period of mechanical ventilation, which requires a long stay in the ICU, and they believe moderating these two factors will make it possible to control the costs and prevent complications resulting from long ventilation periods and lengthy stay in the ICU while in their study; [2] which revealed that OR time is the most expensive direct variable cost of CABG surgery [5], [6].

In our study there was no significant value with demographic data \& BMI therefore according to our study ultrafast tracking is not significantly affected by age, sex\& BMI while in study conducted by [5] which revealed that age is one of the variables related to the duration of mechanical ventilation in coronary artery bypass surgery. Therefore, nurses should exercise greater care and caution when deciding on extubation time for old patients [5)].

S. Bansal et al., [3] reported two preoperative variables (increased age and female gender) and four postoperative variables (usage of intra-aortic balloon pump, inotropes, excessive bleeding, and atrial arrhythmia) to be associated with delayed extubation. Furthermore, it is to be stated that "every patient who is free of those predictors is a potential candidate for UFTA until proven otherwise [7].
Absence of sever pulmonary HTN in ultrafast tracking sample was not statistically significant while in study by [2] which revealed that absence of severe PHT

found to be associated with early extubation and were statistically significant [8].

Once ultra-fast tracking in our study playing an important role in reducing ICU stay there were increasing rate of icu readmission with ultra-fast tracking compared to group of ordinary extubation which required close observation of hemodynamics this is consistent with studies argued against ultra-fast tracking; [2] which revealed that extubation in the OR may increase respiratory and cardiac workload and potentially increases the incidence of cardiorespiratory complications such as myocardial ischaemia, tracheal reintubation, hypothermia, shivering, inadequate analgesia, and mortality [6].

This study revealed no statistical significance between 2 groups in mortality rate but there significant diffenerace as regard ventilator related complication that affected only the ordinary group.

\section{Conclusion}

Fast-track extubation is easily possible in ICUs, have a high success rate and can be applied over a diverse range of cardiac surgical procedures. The main prerequisite is proper selection of the patients. If it is done, health-care cost can be reduced drastically without increasing patient risk.

\section{References}

[1] S.D. Gupta, S. Pal, A. Goswami, A comparative study to determine the effect of intravenous magnesium on postoperative bleeding after on pump CABG in patients receiving pre-operative aspirin. Indian J Anaesth, Vol.53(2), PP.197-200,2013.

[2] P.R. Zevola, B. Maier, Improving the care of cardiothoracic surgery patients through advanced nursing skills. Crit Care Nurse, Vol.19(1), PP.2444, 2015.

[3] S. Bansal, H. Thai, C. Hsu, C. Sai-Sudhakar, S. Goldmanet, "Fast Track Extubation Post Coronary Artery Bypass Graft: A Retrospective Review of Predictors of Clinical Outcomes*," World Journal of Cardiovascular Surgery, Vol.3 (2), PP. 81-86,2013.

[4] M. Salah, H. Hosny, M. Salah, H. Saad, Impact of immediate versus delayed tracheal extubation on length of ICU stay of cardiac surgical patients, a 
randomized trial. Heart, Lung and Vessels;vol.7(4), PP.311-319,2015.

[5] M.D.Firoozabadi, A.Ebadi, M.A. Sheikhi, Extubation time and postoperative blood pressure in CABG patient. Bali Medical Journal, Vol.6(1), PP. 186-191,2017.

[6] Akhtar, Irfan , Hamid, Mohammad, Success and failure of fast track extubation in cardiac surgery patients of tertiary care hospital: One year audit. JPMA. The Journal of the Pakistan Medical Association, Vol.59, PP.154-6,2009.

[7] T.T.WONG D, D.C.H.C.CHENG, R.KUSTRA, TIBSHIRANI R, J.KARSKI, J.CARROLL-
MUNRO, Risk factors of delayed extubation, prolonged length of stay in the intensive care unit, and mortality in patients undergoing coronary artery bypass graft with fast-track cardiac anesthesia: A new cardiac risk score. Anesthesiology, Vol.91 (4), PP.936-44, 1999.

[8] A.kandasamy, s.k.ramalingam, h.a. simon , a s.rumugham, b.d. Reddy, krupanandah: Ultra fasttracking versus a conventional strategy in valve replacement surgery. Indian J. Anaesth. Medknow Publications and Media Pvt. Ltd. May, Vol.57 (3), PP.298- 300, 2013. 